\section{See your way through every little detail}

If you think there's nothing new in the way of impression materials for clinicians - think again!

Discover the innovative, transparent injection moulding technique using EXACLEAR together with a flowable, injectable composite such as G-ænial Universal to easily create chairside temporary crowns, bridges or veneers.

EXACLEAR'S extraordinary transparency allows every little detail to be checked, ensuring there are no air blows or gaps around the margins, while the firm but flexible vinyl polysiloxane material prevents the formation of an oxygen inhibition layer, making final polishing that much easier. The injection moulding technique is ideal for treating wear cases or to recreate complex morphologies, with the ability to clearly see and control the injection at all times while treating several teeth simultaneously.

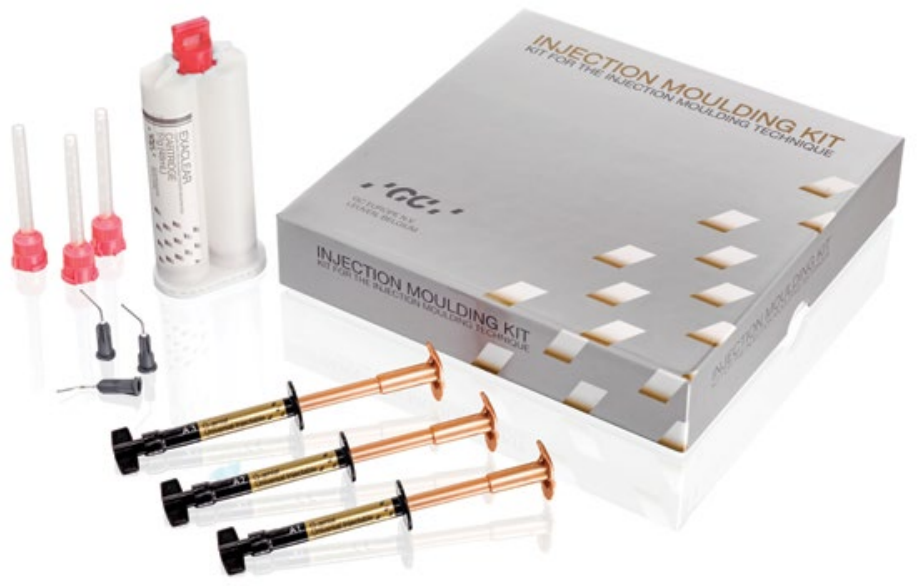

EXACLEAR's ease of handling and rigidity after setting makes it the ideal material for clinicians, orthodontists and implantologists alike.

To find out more contact GC UK Ltd on 01908 218999, email info@gcukltd.co.uk or visit www.gceurope.com.

\section{Seeking CPD tailored to you?}

As a dental hygienist or dental therapist, it can be difficult to find CPD that is directly tailored to your profession.

However, by joining the British Society of Dental Hygiene and Therapy (BSDHT) this doesn't have to be the case!

The BSDHT is renowned for hosting a number of CPD events throughout the country for its members, and also offers access to various journals and other educational materials that often have CPD opportunities.

So if you're looking for high quality CPD that directly relates to your profession, join the BSDHT today and start experiencing the numerous benefits.

For more information about the BSDHT, visit www.bsdht.org uk, call 01788575050 or email enquiries@bsdht.org.uk.

\section{Spend more time doing what you love}

Wouldn't it be great if you had one place to manage all your patient data, stay on top of your diary and carry out your marketing? And it was all securely backed up without you having to worry about it? That's what you get with Dentally.

The team at Dentally understand that running a successful dental practice takes time, and with Dentally there are no more software updates and no lengthy IT admin. Dental practitioners can run faster reports, enjoy efficient charting and all the benefits of simple patient management. So, you get more time doing what you love: helping patients and not sat in front of a computer!

At Dentally we are committed to developing and innovating new ways of making dental practice software simple and easy to use. Time saving product updates introduced over the past few weeks include new reporting, improvements to charting, new waiting lists functionality and updates to the iPad app.

Dentally is trusted by over 4,000 dental professionals in the UK and abroad, who work smarter, work remotely and work securely. For more information about practice management software that saves you time or to arrange a demo visit: http://info.dentally.co/ be-on-cloud-9 or email hello@dentally.co.

\section{Award-winning reliability}

Whenever you choose dental cement you need to ensure that it can give you the strength of hold and longevity you need to be able to supply superior restorations.

Choose an award-winning option with RelyX Unicem 2 self-adhesive resin cement from $3 \mathrm{M}$ Oral Care.

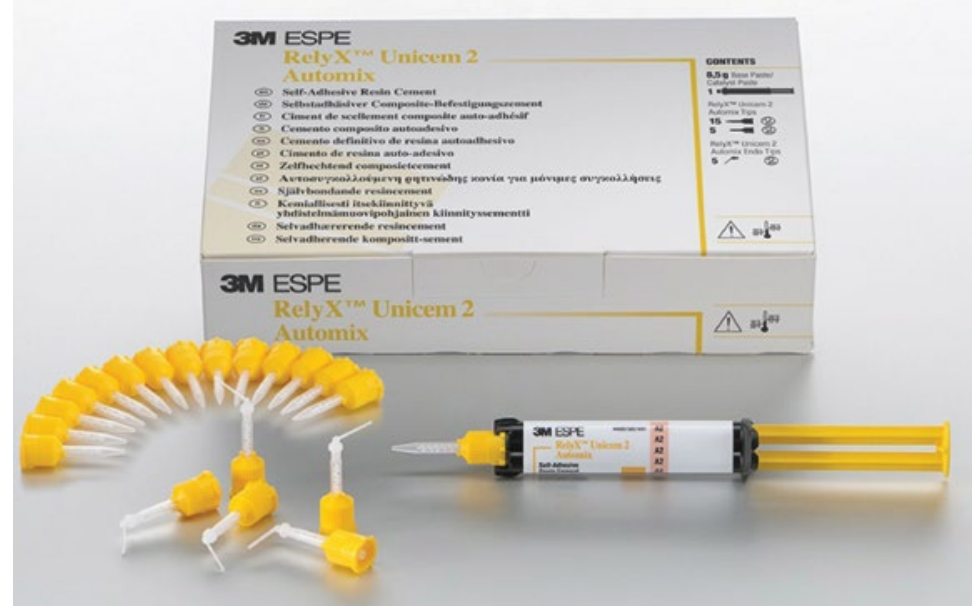

Voted the best long-term performer in the Dental Advisor 2019 product awards, RelyX Unicem 2 self-adhesive resin cement was commended on its lack of post-operative sensitivity and lack of marginal discolouration.

With over 15 years of clinical data, find out more about the award-winning RelyX Unicem 2 self-adhesive resin cement by contacting the team at $3 \mathrm{M}$ Oral Care today.

For more information, call 0800626578 or visit www.3M.co.uk/Dental.

$3 \mathrm{M}$ and RelyX are trademarks of the $3 \mathrm{M}$ Company. 